\title{
Stress in Hospitality Sector and its impact on Employees in context of Uttarakhand
}

\author{
Akanksha Pal ${ }^{1}$ and Avinash Kaur ${ }^{2}$ \\ ${ }^{1}$ Research Scholar, Department of Management, Himgiri Zee University, Dehradun, Uttarakhand. \\ ${ }^{2}$ Assistant Professor, Department of Management, Himgiri Zee University, Dehradun, Uttarakhand. \\ palakanksha1994@gmail.com
}

\begin{abstract}
Uttarakhand is a northern Himalayan state in India with a boon of natural beauty, a place of sublime spirituality and famously known as 'Devbhumi', the Land of Gods. Hospitality is a rapidly expanding industry world-wide, and it is expected to remain a leading contributor to the global economy by generating desired foreign exchange reserves and simultaneously creating employment opportunities. Stress is simply a fact of nature forces from the inside or outside world affecting the individual. The individual responds to stress in ways that affect the individual as well as their environment. A productive employee is considered to be not only a good performer but also highly motivated with a positive attitude. The impact of stress on Performance, Attitude and Motivation is also discussed, it can help the employers too know their employees and empower them accordingly. We in this research study aim to understand the factors relating to satisfaction an dissatisfaction involved in the WLB conditions were they are working in. Further in this research paper we would also develop few techniques and measures which can be used by the hotel industries in future for efficient WLB management of their employees for better productivity and optimization of their human resource.
\end{abstract}

Keywords-Work-life-Balance;Hospitality;Uttarakhand;Employees;Stress;Performance

\section{Introduction}

Stress is a very normal attribute imbibed in each and every human being. Everyone feels stress related to work, family, decisions, future, and more. Stress is both physical and mental entity. It is caused by major life events such as illness, the death of a loved one, a change in responsibilities or expectations at work, and job promotions, loss, or changes. Major workplace and personal stress are inevitable. Smaller, daily events may also cause stress. Researches done throughout the world comes to the fact that stress is not as apparent to anyone, but the constant and cumulative impact of the small stressors adds up to a big impact. This big impact has an effect on subject's physical and mental sense of well-being. If subject allow the negative impact of the large and small stressors to take their toll, subject's physical and mental well-being will suffer.

It was also found by the scholars that in response to these daily stresses, subject's body automatically increases blood pressure, heart rate, respiration, metabolism, and blood flow to 
subject's muscles. This stress response is intended to help the body react quickly and effectively to any high-pressure situation. However, when anyone is constantly reacting to small or large stressful situations, without making physical, mental, and emotional adjustments to counter their effect, one can experience stress that can hurt your health and well-being. It is essential that one understand both of the external and internal stress-causing events, no matter how those events are perceived. It was also found that 'Stress' can also be positive. You need a certain amount of stress to perform your best at work. The key to stress management is to determine the right amount of stress that will give you energy, ambition, and enthusiasm versus the wrong amount of stress which can harm your health, outlook, relationships, and well-being.

While each person is different and has different events and issues that cause stress, there are some issues that almost universally affect people. These are the stressors you most want to understand and take measures to prevent. These are to be mentioned as following feeling out of control, feeling directionless, guilt over procrastination or failing to keep commitments, making more commitments than you have time to keep, making change, especially changes you didn't initiate or institute, uncertainty and high expectations of self.

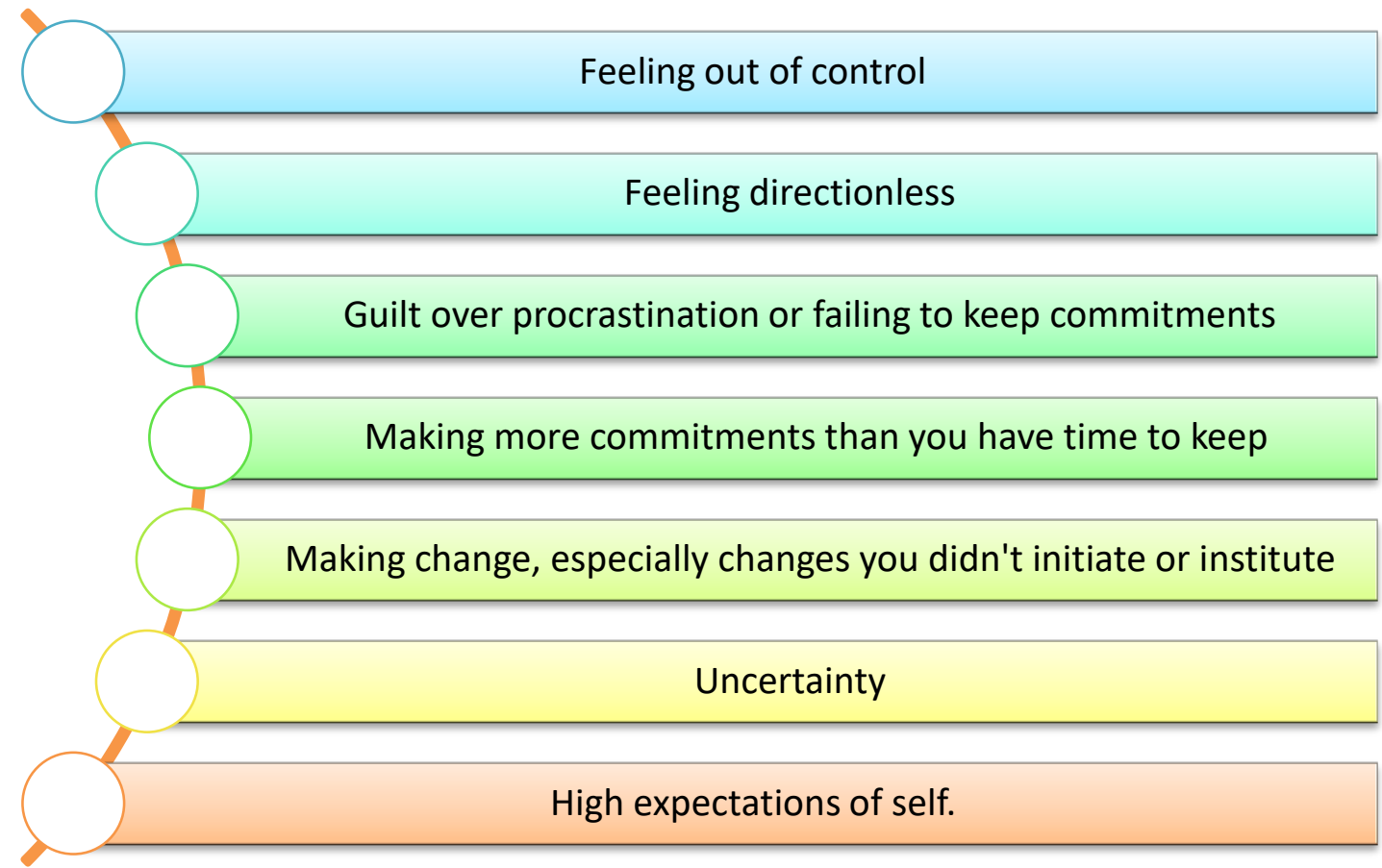

Fig1. Common Stress Generators

\section{Stress : Issues Problem and Opportunity}

During times of stress and uncertainty, one can anticipate some predictable issues, problems, and opportunities. For instance, during any change, members of an organization have:

- Different ways of regarding the change. Some people have difficulty accepting and adjusting to change and uncertainty; others will relish the changes and view them as great opportunities. Some people initiate change; others prefer the status quo. 
- Different amounts of experience and practice in stress management and change management. What is devastating to one individual may excite another or only mildly irritate a third person. Theoretically, people become better at managing stress and change with experience.

- Some people need to "talk it out." Others suffer silently. Some find relief in complaining. Some talk and talk and talk, but are really supportive of the change. Others find ways to sabotage changes and undermine efforts to move forward.

- Different levels of stress and change occurring in other areas of their lives such as family, primary relationships, and health.

- During the change, people will experience different amounts of impact from the current changes and stress-producing situations. They will also experience different amounts and types of support from their spouse, significant other, friends, manager, and co-workers.

All of these and other issues impact one's ability to manage workplace stress and change, to continue to function productively. It is important to recognize that people who are experiencing serious stress and change may not be capable of performing exactly as they have in the past.

\subsection{Stress Results from Change}

People have deep attachments to their workgroups, organizational structures, personal responsibilities, and ways of accomplishing work. When any of these are disturbed, whether by personal choice or through an organizational process from which they may feel quite removed and not involved, a transition period occurs. During this transition, people can expect to experience a period of letting go of the old ways as they begin moving toward and integrating the new.

When you consider stress in the workplace, understanding these components about stress, situations that induce stress, and employee responses to stress can help you help both yourself and your staff effectively manage stress and change.

\subsection{Effects of Stress on Well Being}

Stress can cause physical, emotional, and behavioral problems which can affect your health, energy, well-being, mental alertness, and personal and professional relationships. It can also cause defensiveness, lack of motivation, difficulty concentrating, accidents, reduced productivity, and interpersonal conflict between normally harmonious colleagues.

Too much stress can cause minor problems such as sleep loss, irritability, backaches, or headaches, and can also contribute to potentially life-threatening diseases such as high blood pressure and heart disease.

During stressful times or situations, people often blame themselves for being weak or for their inability "to handle it." Often managers in organizations do not understand the normal progression of change or stress-producing situations and they expect employees to immediately return to total productivity after a stressful event. 


\subsection{Effects of Work Place Stress on Employee Performance}

All of these and other issues impact your ability to manage workplace stress and change, to continue to function productively. It is important to recognize that people who are experiencing serious stress and change may not be capable of performing exactly as they have in the past. Stress can cause physical, emotional, and behavioral problems which can affect your health, energy, well-being, mental alertness, and personal and professional relationships. It can also cause defensiveness, lack of motivation, difficulty concentrating, accidents, reduced productivity, and interpersonal conflict. Too much stress can cause minor problems such as sleep-loss, irritability, backaches, or headaches, and can also contribute to potentially life-threatening diseases such as high blood pressure and heart disease.

During stressful times or situations, people often blame themselves for being weak or for their inability "to handle it." Often managers in organizations do not understand the normal progression of change or stress-producing situations and they expect employees to immediately return to total productivity after a stressful event. It doesn't happen. Managers need to understand that adjustment to change is an individual experience and provide support to a wide range of people who are experiencing diverse feelings.

\section{Research Methodology}

In the research study the primary data is collected from the employees working in the hotels of Uttarakhand. The data is collected through the 'Questionnaire method' as well as observing their behavior. This research study is exploratory as well as descriptive in nature and an effort to analyze the association between the factors related to hotel industry in Uttarakhand. Sample size in the research study consists of around 430 employees. 60 top level , 180 middle level and 150 lower level employees from 40 star category or equivalent to star category service hotels have been taken for the study. As the study requires survey of hotels employees in Uttarakhand state, multi stage random sampling is applicable.

\section{Stress in Hospitality Sector and its impact on Employees}

In this research study our aim was to analyze the stress level from which the employees in the hospitality sectors are suffering from. As already stated in section 3 that the primary data is collected through questionnaire method. The subjects/respondents were asked to provide the information about- Is stress in hospitality sector is a significant issue? Is stress is a real problem at work place(hotels)?

\begin{tabular}{|c|c|c|}
\hline Is 'Stress' in hospitality sector is a significant issue? & Frequency & Percent \\
\hline Yes & 308 & 77 \\
\hline No & 92 & 23 \\
\hline
\end{tabular}

Table 1. Is 'Stress' in hospitality sector is a significant issue 


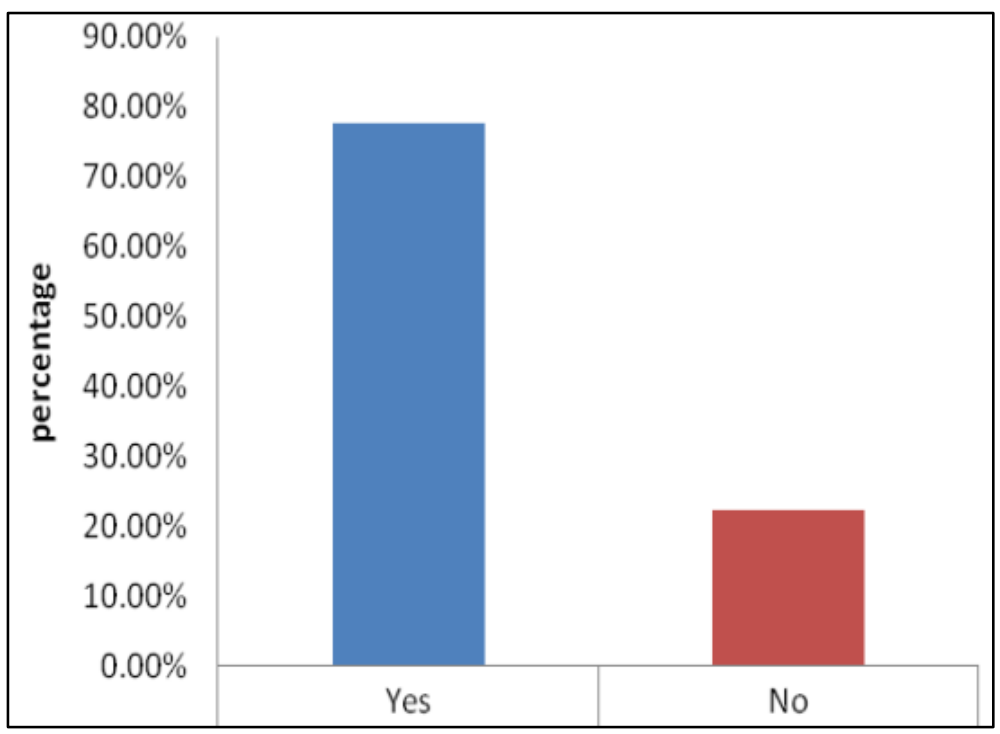

Fig 1. Is 'Stress' in hospitality sector is a significant issue

Further we got into our further requirements with the respondents and discussed about how they feel in relation with the effects of Stress on few attributes such as Performance and Attitude. These responses were noted, analyzed and henceforth demonstrated graphically in following tables and figures.

\subsection{Impact of Stress on Employees Performance and Attitude}

The primary data is collected through questionnaire method. The subjects/respondents were at first asked to provide the information about- Is stress in hospitality sector is a significant issue? Is stress is a real problem at work place(hotels)? After the stage first of our research we came forth towards the next part of the research. During this phase we talked about the areas such as how the stress palpable in this sector affects their performance and work culture throughout .

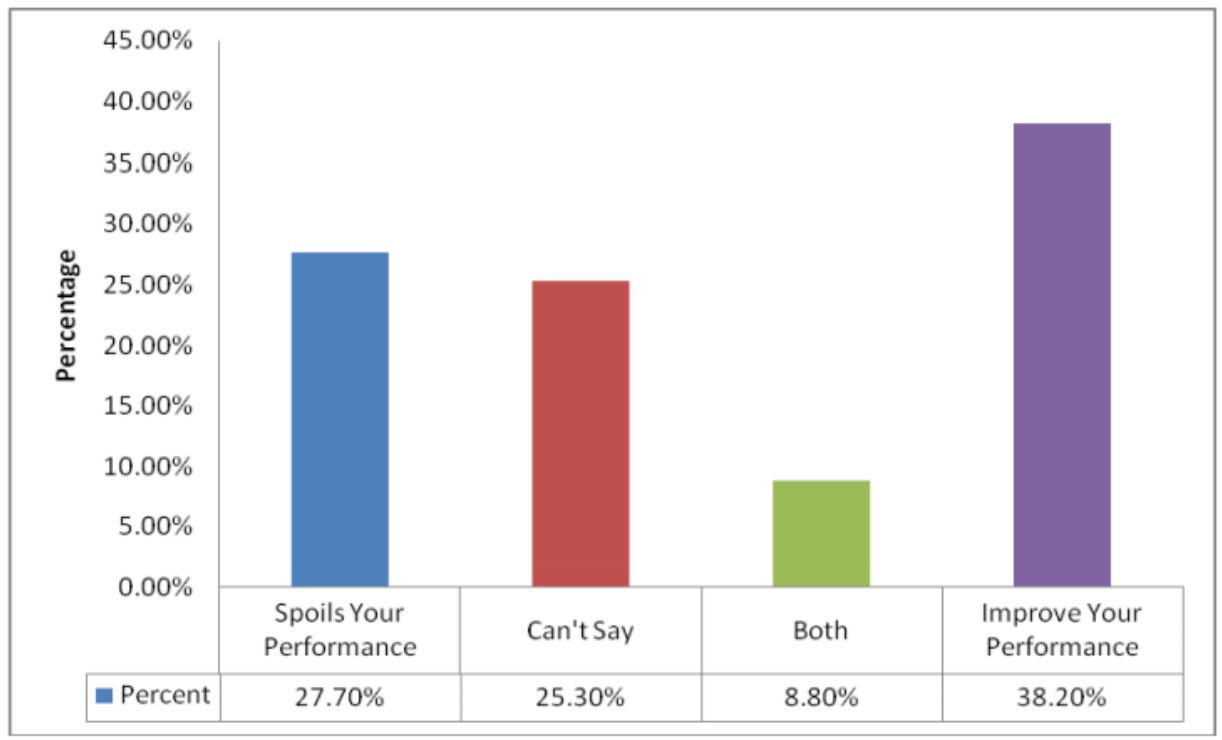

Figure2. Effect of Stress on the Performance 
As clearly mentioned $27.7 \%$ of the respondents were sure that Stress actually spoils one's performance whereas majority of them i.e. $38.20 \%$ were affirmed to the fact that it actually improves ones performance. Whereas $8.8 \%$ of them gave the fact that it depends on the context and level as well as kind of stress we are talking about.

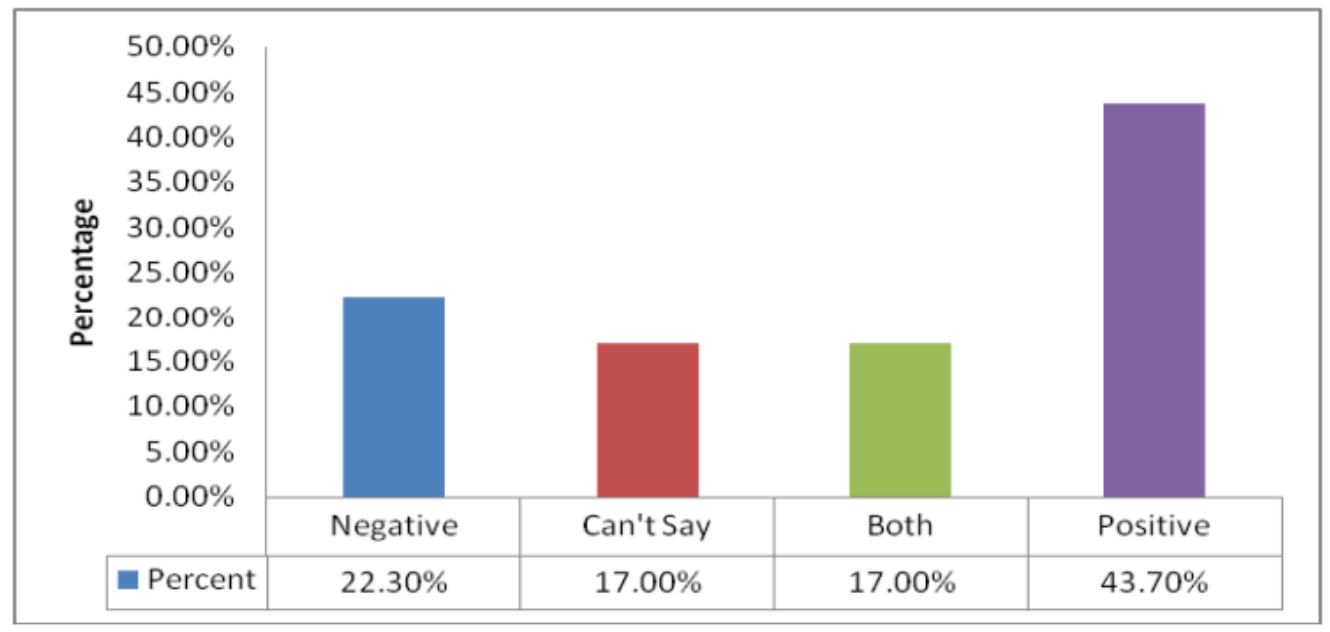

Figure3. Effect of Stress on the Attitude

Our next target was to analyze the effect of 'stress' on the next taken attribute i.e. attitude. We came to the conclusion as demonstrated in figure 3 that majority $(43.7 \%)$ of respondents were to the belief that in actually has the positive impact on the attitude of the employees altogether, whereas $22.30 \%$ were convinced that it is actually detrimental to the work attitude.

\section{Results and Discussion}

Many of the researchers and scholars of the related fields are of the opinion that stress is normal and necessary. However, too much will affect productivity, causing product defects, service delivery problems and other operational metrics to suffer. Consequences of too much stress include absenteeism and employee turnover, employee mistakes, interpersonal conflicts and employee anxiety. Stress aggravates existing challenges and can spread to disrupt an entire team. By prioritizing tasks, breaking large projects into smaller components and delegating responsibility as appropriate, employees can learn to let go of controlling everything, which can create unnecessary stress. By resisting perfectionism, people can also avoid unnecessary pressure that is often self-imposed. By reducing clutter, maintaining to-do lists and thinking positively about interactions, employees can regain energy and motivation necessary to function effectively at work and at home. 

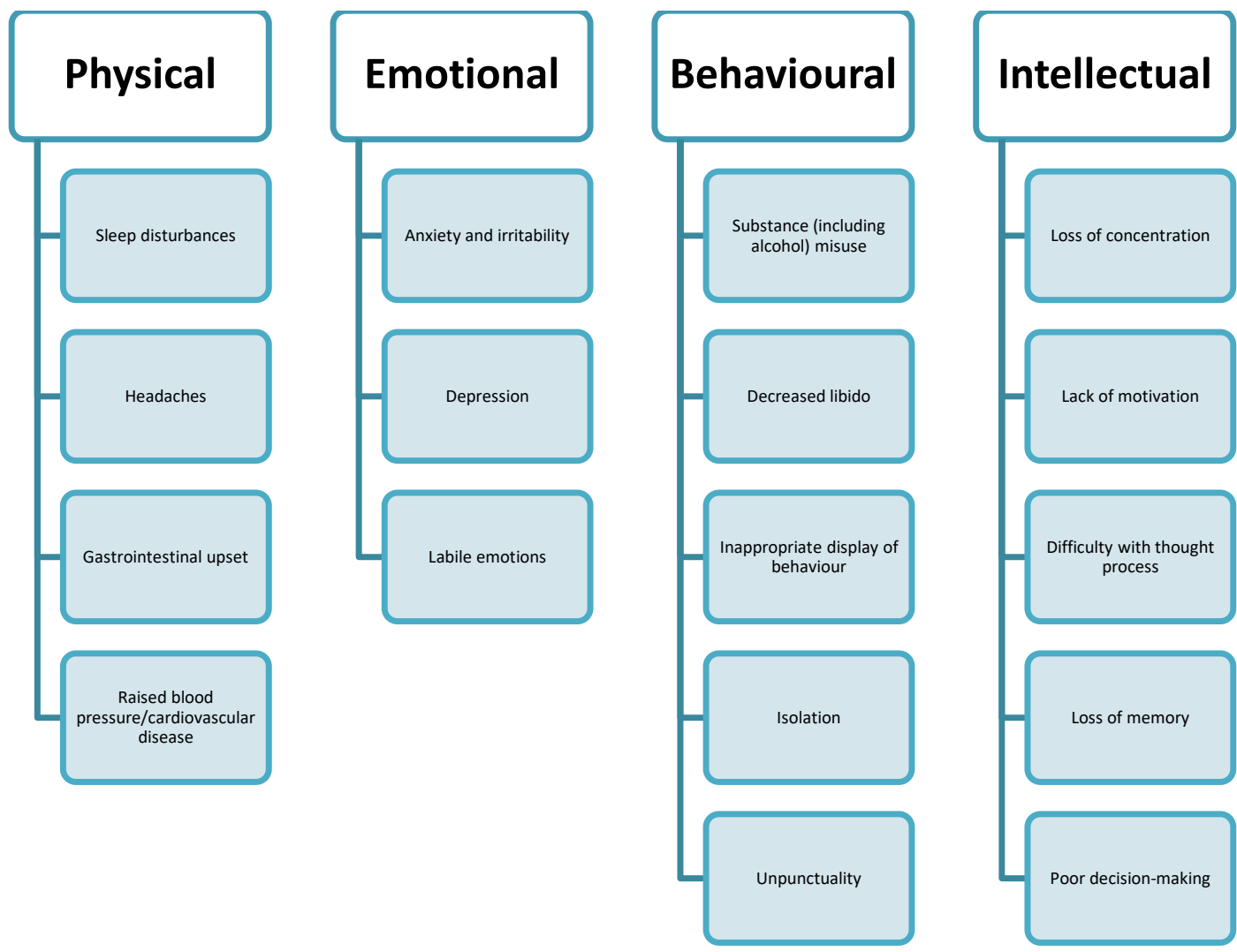

Fig 4. Negative effects of Stress on the Employees

\section{Conclusion}

Workplace stress is preventable and identifying the potential sources of stress to employees in hotels is the first step in addressing them. Effective interventions for reducing workplace stress can be classified as primary, secondary, and tertiary.

Primary interventions involve proactive measures to prevent stress by removing or reducing potential stressors. This level of intervention focuses on the sources of physical and psychosocial stress in the workplace. Examples of primary interventions include: Redesigning the work environment, Providing breaks and nap-times for employees, Increasing employee participation in decision making and work planning, Increasing time and resources for completing specific job tasks, Matching job description with employee skills and qualifications, Creating clear promotion and reward pathways, Eliminating physical hazards, Substituting with safer equipment and technology, Establishing control measures to reduce worker's exposure to occupational hazards and Promoting the use of personal protective equipment

Secondary interventions are corrective and are focused on altering the ways workers perceive and respond to stressors. These interventions aim at improving worker's ability to cope with stress and detect stress-induced symptoms early. Examples of secondary interventions include: Training and education of employees, Cognitive behavioral therapy training for workers and Routine health surveillance - screening for high blood pressure 
and stress symptoms

Tertiary interventions are forms of control at the level of the illness. These are initiated for workers who are already experiencing stress. Tertiary interventions involve providing treatment, compensation plans, rehabilitation programs, and return to work programs for affected workers. Tertiary interventions include steps such as Providing medical care and employee assistance programs to affected workers and Return-to-work plans including modification and redesign of work

\section{References}

[1] David Dann, , Timothy Hornsey(1986), Towards a theory of interdepartmental conflict in hotels, International Journal of Hospitality Management, Vol 5, Issue 1, 1986, Pages 23-28

[2] Taylor \& Francis (1986), Hotel Manager - An Unsuitable Job for a Woman - The Service Industries Journal - Vol 6, Issue 2

[3] Richard S. DeFrank, Cary L. Cooper, (1987) "Worksite Stress Management Interventions:: Their Effectiveness and Conceptualisation", Journal of Managerial Psychology, Vol. 2 Iss: 1, pp. $4-10$

[4] Mort Sarabahksh1,David Carson2 and Elaine Lindgren3, Hospitality Managers' Stress and Quality of Life: Recommendations for Change,Journal of Hospitality \& Tourism Research August 1989 vol. 13 no. 3 239- 245

[5] Robert A Brymer, Pamela L Perrewe, Tony R Johns(1991), Managerial job stress in the hotel industry,International Journal of Hospitality Management,Vol 10, Issue 1, 1991, Pages 47-58

[6] Dov Zohar,(1994), Analysis of job stress profile in the hotel industry, International Journal of Hospitality Management, Vol 13, Issue 3, September 1994, Pages 219-231

[7] Taylor \& Francis (1995),Interpersonal Stress Reactions and Service Quality Responses among Hospitality Industry Employees, The Service Industries Journal Vol 15, Issue 3, 1995

[8] Glenn F. Ross, (1995) "Work stress and personality measures among hospitality industry employees", International Journal of Contemporary Hospitality Management, Vol. 7 Iss: 6, pp. $9-13$

[9] Ross, Glenn F(1995).Interpersonal stress reactions and service quality responses among hospitality industry employees, The Service Industries Journal

[10] Darren Lee-Ross, Nick Johns, (1997) "Yield management in hospitality SMEs", International Journal of Contemporary Hospitality Management, Vol. 9 Iss: 2, pp.66 - 69

[11] Hadyn Ingram, (1997) "Performance management: processes, quality and teamworking", International Journal of Contemporary Hospitality Management, Vol. 9 Iss: 7, pp.295 - 303 
[12] Bill Faulkner, Anoop Patiar,(1997),Workplace induced stress among operational staff in the hotel industry,International Journal of Hospitality Management,Vol 16, Issue 1, March 1997,,Pages 99-117

[13] Abraham Pizam, ,Steven W Thornburg(2000), Absenteeism and voluntary turnover in Central Florida hotels: a pilot study, International Journal of Hospitality Management, Vol 19, Issue 2, June 2000, Pages 211-217

[14] 14 Helen Atkinson, Jackie Brander Brown, (2001) "Rethinking performance measures: assessing progress in UK hotels", International Journal of Contemporary Hospitality Management, Vol. 13 Iss: 3, pp.128 - 136

[15] Ian Buick, Mahesh Thomas, (2001) "Why do middle managers in hotels burn out?", International Journal of Contemporary Hospitality Management, Vol. 13 Iss: 6, pp.304 -309

[16] Amarjit S. Gill, Alan B. Flaschner, Mickey Shachar(2006), Mitigating stress and burnout by implementing transformational-leadership,,International Journal of Contemporary Hospitality Management, Vol: 18 Issue: 6 Page: 469 -481 